\title{
Structure and Dynamics of Iron Pentacarbonyl
}

Peter Portius, ${ }^{* \dagger,}{ }^{\circ}$ Michael Bühl, ${ }^{\ddagger}$ Michael W. George, ${ }^{\S, \| \odot ~ F r i e d r i c h-W i l h e l m ~ G r e v e l s, ~}{ }^{\perp, \#}$ and James J. Turner*,

${ }^{\dagger}$ Department of Chemistry, The University of Sheffield, Western Bank, Sheffield S3 7HF, United Kingdom

${ }^{\ddagger}$ School of Chemistry, University of St. Andrews, St. Andrews, Fife KY16 9ST, United Kingdom

${ }^{\S}$ School of Chemistry, University of Nottingham, University Park, Nottingham NG7 2RD, United Kingdom

"Department of Chemical and Environmental Engineering, University of Nottingham Ningbo China, 199 Taikang East Road, Ningbo 315100, China

${ }^{\perp}$ Max-Planck-Institut für Bioanorganische Chemie, Stiftstraße 34-36, D-45470 Mülheim an der Ruhr, Germany

\section{Supporting Information}

ABSTRACT: The dynamics of $\mathrm{CO}$ ligand scrambling in $\mathrm{Fe}(\mathrm{CO})_{5}$ has been investigated by linear infrared spectroscopy in supercritical xenon solution. The activation barrier for the Berry pseudorotation in $\mathrm{Fe}(\mathrm{CO})_{5}$ was determined experimentally to be $E_{\mathrm{a}}=2.5 \pm 0.4 \mathrm{kcal} \mathrm{mol}^{-1}$ by quantitative analysis of the temperature-dependent spectral line shape. This compares well with the range of $E_{\mathrm{a}} /\left(\mathrm{kcal} \mathrm{mol}^{-1}\right)=2.0$ to 2.3 calculated by various DFT methods and the value of $1.6 \pm 0.3$ previously obtained from 2D IR measurements by Harris et al. (Science 2008, 319, 1820). The involvement of $\mathrm{Fe}(\mathrm{CO})_{5} \cdots \mathrm{Xe}$ interactions in the ligand scrambling process was tested computationally at the BP86-D3/ AE2 level and found to be negligible.

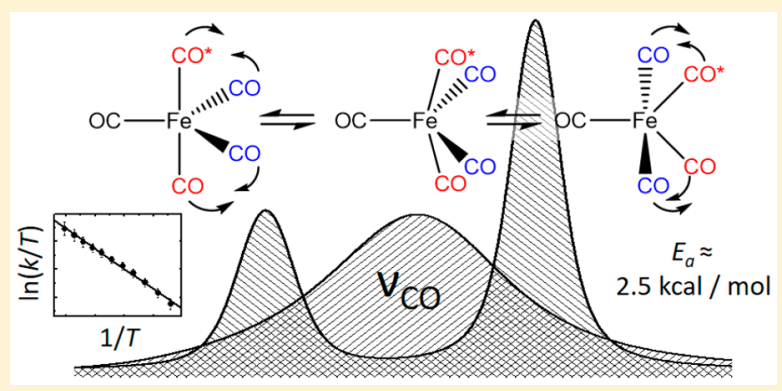

\section{INTRODUCTION}

Since the synthesis of $\mathrm{Fe}(\mathrm{CO})_{5}$ in $1891,{ }^{1}$ there has been a great deal of interest in its chemistry, structure, and bonding, in particular the dynamics of the scrambling of the ligands. $\mathrm{Fe}(\mathrm{CO})_{5}$ has a $D_{3 h}$-symmetric structure in the gas phase (cf. Figure 1). ${ }^{2}$ In 1958, Cotton et al. ${ }^{3}$ observed that the ${ }^{13} \mathrm{C}$ NMR

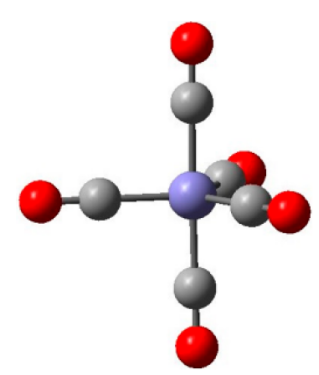

Figure 1. Ball-and-stick model of the $D_{3 h}$-symmetric structure of $\mathrm{Fe}(\mathrm{CO})_{5}$. Fe, lilac; C, gray; O, red.

spectra showed only one line at all available temperatures. Later work ${ }^{4}$ confirmed and extended this down to $-170{ }^{\circ} \mathrm{C}$. Thus, the exchange among the $\mathrm{CO}$ groups must be very fast. In rather subtle NMR experiments, Sheline and Mahnke ${ }^{5}$ estimated that at room temperature, $\mathrm{CO}$ scrambling occurs at a rate of about $1.1 \times 10^{10} \mathrm{~s}^{-1}$ with an activation energy of $\sim 1.13 \mathrm{kcal} \mathrm{mol}^{-1}$.
It is usually assumed that the mechanism involves the Berry pseudorotation $^{6}$ (Figure 2). Attempts to resolve the structure

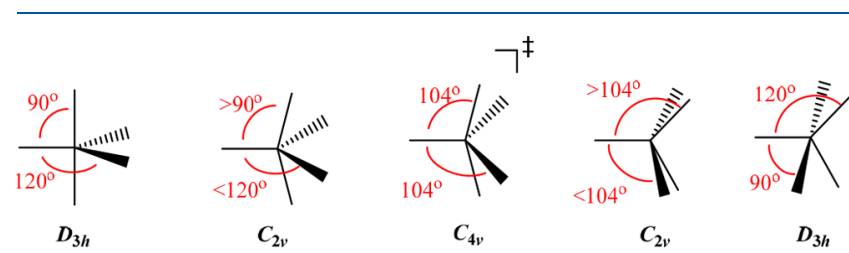

Figure 2. Geometries relevant for the Berry pseudorotation model of $\mathrm{Fe}(\mathrm{CO})_{5}$ and for the DFT calculations in this paper.

have been carried out in the solid state at low temperature and have resulted in some disagreement, ${ }^{7,8}$ which is, however, of little relevance to understanding the behavior in solution. That it was possible to freeze the scrambling was shown by Turner and colleagues ${ }^{9}$ using a combination of polarized photolysis and IR spectroscopy in a $\mathrm{CO}$ matrix at $20 \mathrm{~K}$.

A large number of DFT calculations on $\mathrm{Fe}(\mathrm{CO})_{5}$ (and other metal carbonyls) have been carried out. Most of them were concerned with structure, and particularly with the difference between the axial and equatorial $\mathrm{Fe}-\mathrm{C}$ and $\mathrm{C}-\mathrm{O}$ bond lengths as well as the dissociation energy of the ligand decoordination reaction, $\mathrm{Fe}(\mathrm{CO})_{5} \rightarrow \mathrm{Fe}(\mathrm{CO})_{4}+\mathrm{CO}$, and the vibrational

Received: August 16, 2019

Published: October 17, 2019 
frequencies. Several authors have considered the energy difference between the $D_{3 h}$-symmetric ground state and the top of the barrier in the Berry mechanism $\left(C_{4 v}\right)$. Schaefer and colleagues ${ }^{10}$ calculated the barrier height using various basis sets and obtained values of $2.25 \mathrm{kcal} \mathrm{mol}^{-1}$ (DZ B3LYP), 2.28 $\mathrm{kcal} \mathrm{mol}^{-1}$ (DZP BP86), and $2.33 \mathrm{kcal} \mathrm{mol}^{-1}$ (DZP B3LYP) with the stated methods. In an important paper, Harris and coworkers $^{11}$ estimated the barrier height to be $2.13 \mathrm{kcal} \mathrm{mol}^{-1}$ (BP86 with the basis sets $6-31+\mathrm{G}(\mathrm{d})$ for $\mathrm{C}$ and $\mathrm{O}$, and LANL2DZ for Fe). More recently, Couzijn et al. ${ }^{12}$ obtained a value of $2.0 \mathrm{kcal} \mathrm{mol}^{-1}$ at the B3PW91/SDD(d) level of theory. The relevance of these data will be outlined shortly. We have calculated the barrier height at the BP86, PBE, PBE0, and $\operatorname{CCSD}(\mathrm{T})$ levels of theory and obtained values between 2.0 and $2.3 \mathrm{kcal} \mathrm{mol}^{-1}$; see the Supporting Information (SI) for details of the calculations. Thus, the calculation of the barrier height is remarkably independent of the DFT method. However, obtaining good experimental data for the barrier height and the kinetics of the Berry pseudorotation is a much more challenging problem.

The study of dynamics requires experiments to be conducted over a broad range of temperatures, and with very small barriers in particular, one needs to be able to extend this to very low ones. While there is no doubt that the structure of $\mathrm{Fe}(\mathrm{CO})_{5}$ in the gas phase has $D_{3 h}$ symmetry, the complex can undergo considerable distortion in various solvents. Elegant experiments by Rose-Petruck and colleagues ${ }^{13}$ using IR spectroscopy probed the temperature dependence of the spectrum in the region of the $\nu(\mathrm{CO})$ stretches. With the support of DFT calculations, they were able to show that particularly in benzene and increasingly fluorinated derivatives, the structure of $\mathrm{Fe}(\mathrm{CO})_{5}$ distorts to $C_{2 v^{-}}$or $C_{4 v^{-}}$-symmetric geometries. The authors also supplied thermodynamic parameters connecting the $D_{3 h}$ structure with the various distorted structures as shown in eq 1 :

$$
\underset{\left(D_{3 h}\right)}{\mathrm{Fe}(\mathrm{CO})_{5}+\text { solvent }} \rightarrow \underset{\left(C_{2 v} / C_{4 v}\right)}{\mathrm{Fe}(\mathrm{CO})_{5} \cdots \text { solvent }}
$$

In pentafluorobenzene, for instance, the parameters $\Delta H=$ $-3.59 \pm 0.68 \mathrm{kcal} \mathrm{mol}^{-1}, \Delta S=-8.43 \pm 1.83 \mathrm{cal} \mathrm{K}^{-1} \mathrm{~mol}^{-1}$, and $\Delta \bar{G}=-1.08 \mathrm{kcal} \mathrm{mol}^{-1}$ can be used to describe the equilibrium between the two structures at room temperature. According to these data, it can be concluded that the equilibrium lies well to the right $\left(10.6 \% D_{3 h}, 89.4 \% C_{2 v}\right)$ and that the $\nu(\mathrm{CO})$ IR spectrum is dominated by the distorted structure. However, as the temperature is raised, and assuming $\Delta H$ remains roughly constant, the negative entropy change will cause a shift of the equilibrium to the left. If the interaction between $\mathrm{Fe}(\mathrm{CO})_{5}$ and cyclohexane is presumed to be weak, it is not surprising that the experimental evidence for a complex is weak, and the authors concluded that at room temperature, $\mathrm{Fe}(\mathrm{CO})_{5}$ is "nearly undisturbed $D_{3 h}$ " in cyclohexane. ${ }^{13}$ With the negative entropy changes being involved, there will be an even lesser distortion of the structure at higher temperatures. However, since this paper is concerned with the dynamic behavior of $\mathrm{Fe}(\mathrm{CO})_{5}$, more information is needed about both structures and spectra in a variety of solvents. The following describes new experimental and computational evidence for the barrier in this prototypical fluxional molecule.

\section{RESULTS AND DISCUSSION}

Figure 3 shows the $\nu(\mathrm{CO})$ region of the IR spectrum of $\mathrm{Fe}(\mathrm{CO})_{5}$ in 2 -methylpentane at $-140^{\circ} \mathrm{C}$. The bands labeled 1

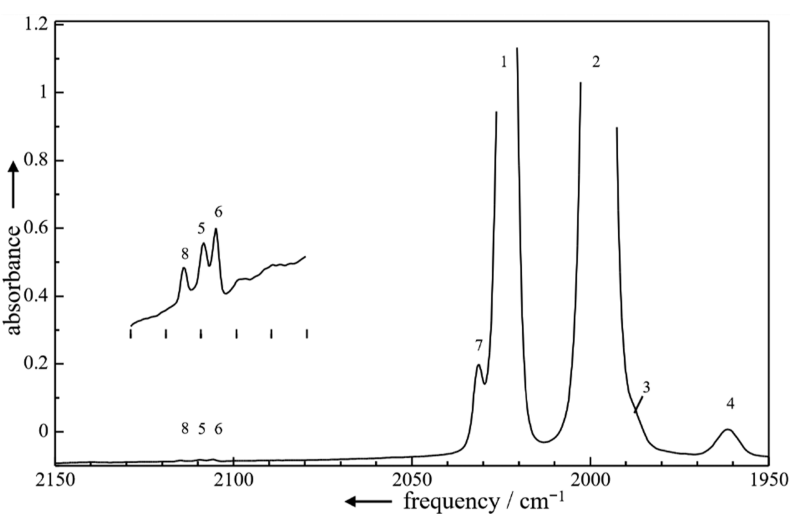

Figure 3. IR spectrum in the $\nu(\mathrm{CO})$ region of $\mathrm{Fe}(\mathrm{CO})_{5}$ in 2 methylpentane at $-140{ }^{\circ} \mathrm{C}$.

and 2 are assigned to the $\nu(\mathrm{CO})$ vibrations that transform as the $\mathrm{a}_{2}^{\prime \prime}$ and $\mathrm{e}^{\prime}$ irreducible representations of $D_{3 h^{-}}$-symmetric $\mathrm{Fe}\left({ }^{12} \mathrm{CO}\right)_{5}$, respectively; those labeled 3, 4, 5, 6 arise from $\mathrm{Fe}\left({ }^{13} \mathrm{CO}\right)\left({ }^{12} \mathrm{CO}\right)_{4}$ (see the SI for a full force constant analysis) due to naturally occurring ${ }^{13} \mathrm{CO} .{ }^{14,15}$ The two fundamental $\mathrm{a}^{\prime}$ $\nu(\mathrm{CO})$ vibrations are not active in the IR under $D_{3 h}$ symmetry but become active if the symmetry is reduced slightly to $C_{2 v}$; the bands labeled 7 and 8 are assigned to these $a^{\prime}$ vibrations. If the distortion is considerable, the degeneracy of the $\mathrm{e}^{\prime}$ vibrations is removed.

As the temperature is raised, bands 7 and 8 disappear because the concentration of the distorted structure decreases (see Figure 4). It should also be noted that bands 5 and 6

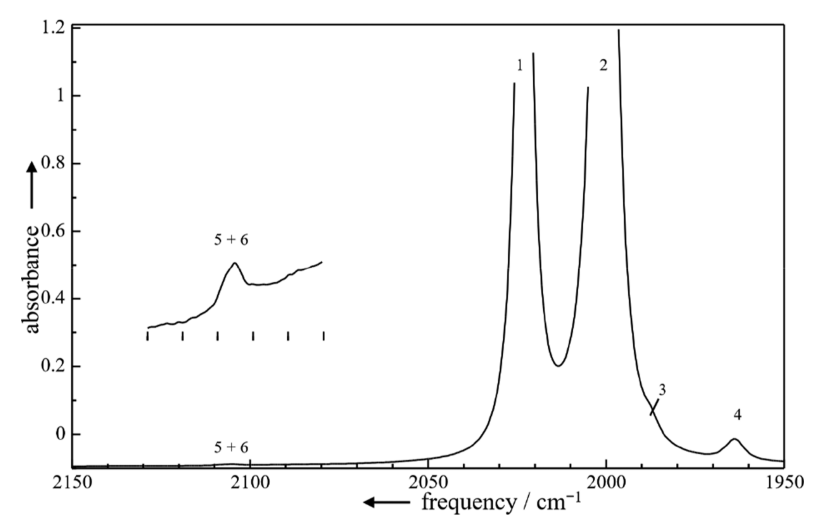

Figure 4. IR spectrum in the $\nu(\mathrm{CO})$ region of $\mathrm{Fe}(\mathrm{CO})_{5}$ in 2methylpentane at $20{ }^{\circ} \mathrm{C}$.

appear to have coalesced at this temperature- $-a$ fact that will be discussed at a later stage. However, caution must be exercised in using even saturated hydrocarbons as supposedly inert solvents. What solvents could be used? Figure 5 shows the spectra of $\mathrm{Fe}(\mathrm{CO})_{5}$ in liquid krypton and at two different concentrations in liquid xenon.

It is clear that even at this low temperature there is no evidence for bands 7 and 8 . Under the assumption that $\Delta S$ is negative (see later), the concentrations of $\mathrm{Fe}(\mathrm{CO})_{5} \cdots \mathrm{Kr}$ and $\mathrm{Fe}(\mathrm{CO})_{5} \cdots \mathrm{Xe}$ will be zero at room temperature and above. It will be shown later that an accurate force field is required for the investigation of the dynamics of $\mathrm{Fe}(\mathrm{CO})_{5}$. The assignment of the energy-factored force constants of $\mathrm{Fe}(\mathrm{CO})_{5}$ is straightforward and follows that of Bor. ${ }^{15}$ The details of the calculation are given in the SI. Since the experiments described 

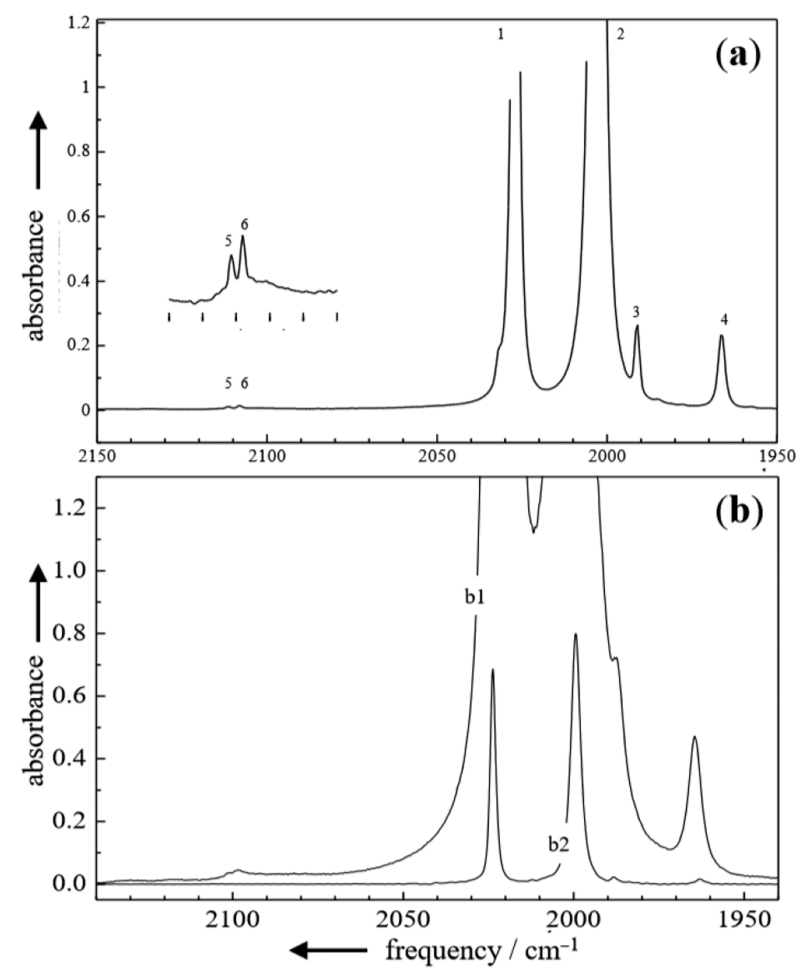

Figure 5. IR spectra of $\mathrm{Fe}(\mathrm{CO})_{5}$ in the $\nu(\mathrm{CO})$ region in (a) liquid krypton at $-138{ }^{\circ} \mathrm{C}$ and (b) liquid xenon at $-107{ }^{\circ} \mathrm{C}$ at the concentrations $c(\mathrm{~b} 1)$ and $c(\mathrm{~b} 2)$ with $c(\mathrm{~b} 1) / c(\mathrm{~b} 2) \approx 40$.

in this paper were performed in liquid xenon, we provide the force constants in this medium in Table 1.

Table 1. C-O IR Frequencies (in $\mathrm{cm}^{-1}$ ) and EnergyFactored Force Constants $\left(\right.$ in $\left.\mathrm{N} \mathrm{m}^{-1}\right)$ for $\mathrm{Fe}(\mathrm{CO})_{5}$ in Liquid $\mathrm{Xe}$

\begin{tabular}{|c|c|c|c|}
\hline isomer & $\begin{array}{l}\text { Frequencie } \\
\text { band no. }\end{array}$ & symmetry & $\nu / \mathrm{cm}^{-1}$ \\
\hline \multirow[t]{2}{*}{$\mathrm{Fe}\left({ }^{12} \mathrm{CO}\right)_{5}$} & 1 & $a_{2}^{\prime \prime}$ & 2023.9 \\
\hline & 2 & $\mathrm{e}^{\prime}$ & 1999.6 \\
\hline \multirow[t]{2}{*}{$a x-\mathrm{Fe}\left({ }^{13} \mathrm{CO}\right)\left({ }^{12} \mathrm{CO}\right)_{4}$} & 3 & $a_{1}$ & 1988.5 \\
\hline & 6 & $a_{1}$ & 2106.1 \\
\hline \multirow[t]{2}{*}{ eq- $\mathrm{Fe}\left({ }^{13} \mathrm{CO}\right)\left({ }^{12} \mathrm{CO}\right)_{4}$} & 4 & $a_{1}$ & 1963.2 \\
\hline & 5 & $\mathrm{a}_{1}$ & 2109.4 \\
\hline \multicolumn{4}{|c|}{ Force Constants } \\
\hline$k_{\mathrm{ax}}$ & & \multicolumn{2}{|l|}{1698.1} \\
\hline$k_{\text {eq }}$ & & \multicolumn{2}{|l|}{1655.2} \\
\hline$k_{\mathrm{ax}, \mathrm{ax}}$ & & \multicolumn{2}{|l|}{43.4} \\
\hline$k_{\text {eq,eq }}$ & & \multicolumn{2}{|c|}{39.9} \\
\hline$k_{\mathrm{ax}, \mathrm{eq}}$ & & \multicolumn{2}{|c|}{28.0} \\
\hline
\end{tabular}

For technical and safety reasons, it is easier to study $\mathrm{Fe}(\mathrm{CO})_{5}$ at higher temperatures in liquid Xe rather than liquid $\mathrm{Kr}$. In examining the dynamical behavior of $\mathrm{Fe}(\mathrm{CO})_{5}$ in liquid $\mathrm{Xe}$, it is worth probing the possible interaction of $\mathrm{Fe}(\mathrm{CO})_{5}$ with $\mathrm{Xe}$, particularly as the molecule distorts in the process of the Berry pseudorotation. As a first step toward modeling the bulk liquid, we investigated the interaction between $\mathrm{Fe}(\mathrm{CO})_{5}$ and a single Xe atom. The result of the DFT calculation (see SI for details) is displayed in Figure 6 and shows how the interaction energy depends on the distance between Xe and $\mathrm{Fe}(\mathrm{CO})_{5}$ and that the interaction is essentially caused by

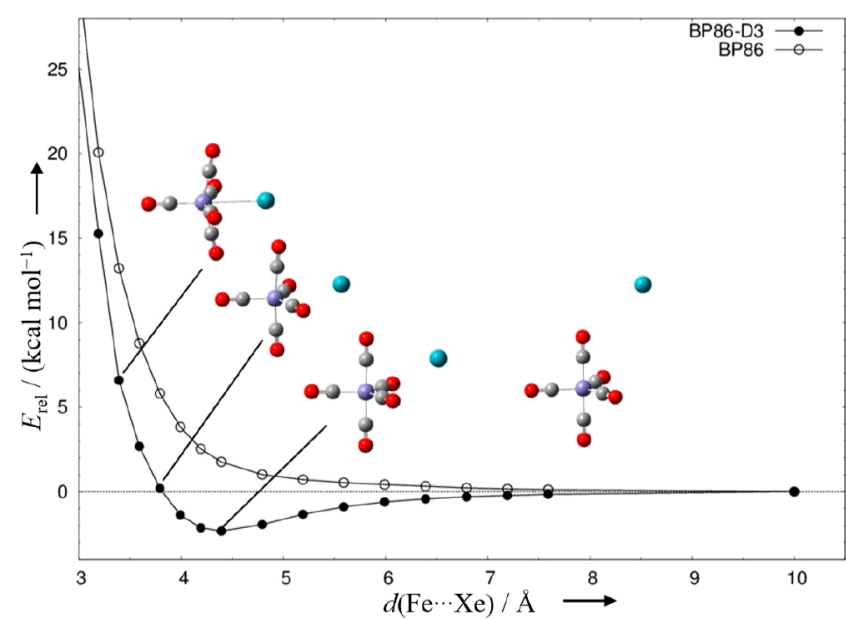

Figure 6. Energy profile for $\mathrm{Fe}(\mathrm{CO})_{5} \cdots \mathrm{Xe}$ as a function of the $\mathrm{Fe}(\mathrm{CO})_{5} \cdots \mathrm{Xe}$ distance (all other parameters optimized) calculated at the BP86/AE2 $(\mathrm{O})$ (a purely repulsive potential) and BP86-D3/AE2 (๑) levels.

attractive van der Waals-type dispersion interactions. Furthermore, in agreement with the observation made by IR spectroscopy, the optimized geometries indicate no effective distortion of $\mathrm{Fe}(\mathrm{CO})_{5}$ (at least not until the $\mathrm{Xe} \cdots \mathrm{Fe}(\mathrm{CO})_{5}$ distance is very small, below ca. $3.5 \AA$ ).

The important question, however, is how the interaction could affect the $C_{4 v}$-symmetric structure at the transition state of the Berry mechanism and therefore the $D_{3 h}-C_{4 v}$ barrier height. Table 2 shows the results of our DFT calculations.

Table 2. Energy Barriers for Pseudorotation ${ }^{a}$ in $\mathrm{Fe}(\mathrm{CO})_{5}$ and $\mathrm{Fe}(\mathrm{CO})_{5} \cdots \mathrm{Xe}$ at the BP86-D3/AE2 Level of Theory

$\begin{array}{ccc}\text { energy }^{b} & \mathrm{Fe}(\mathrm{CO})_{5} & \mathrm{Fe}(\mathrm{CO})_{5} \cdots \mathrm{Xe} \\ \Delta E(0 \mathrm{~K}) & 2.2 & 2.0 \\ \Delta H(298 \mathrm{~K}) & 1.6 & 1.4 \\ \Delta G(298 \mathrm{~K}) & 2.9 & 3.2\end{array}$

${ }^{a}$ Evaluated as the difference between the $D_{3 h}$-symmetric minimum and the $C_{4 v}$-symmetric transition state for $\mathrm{Fe}(\mathrm{CO})_{5}$ and between the $C_{s}$-symmetric minimum shown in Figure 6 and a $C_{4 v}$-symmetric transition state (not shown) for $\mathrm{Fe}(\mathrm{CO})_{5} \cdots$ Xe. ${ }^{b}$ In units of kcal $\mathrm{mol}^{-1}$.

Only very small energy differences of $0.3 \mathrm{kcal} \mathrm{mol}^{-1}$ or less were found upon evaluation of the structures of $\mathrm{Fe}(\mathrm{CO})_{5}$ and Xe in either the $D_{3 h}$ or $C_{4 v}$ geometry. It is therefore clear that in the two structures, within the limits of the calculations, ${ }^{16}$ the interactions between $\mathrm{Fe}(\mathrm{CO})_{5}$ and $\mathrm{Xe}$ are of a similar nature. Even though this calculation refers to the gas phase, in view of the nature of the $\mathrm{Xe}-\mathrm{Fe}(\mathrm{CO})_{5}$ interaction it is unlikely that the $\mathrm{Xe}$ supercritical fluid environment will make a large difference to the parameters. Moreover, because the entropy change for complex formation will be negative, the concentration of a $\mathrm{Xe}$ complex at room temperature and above will certainly be close to zero.

Obtaining good experimental data for the kinetics and barrier height for the Berry pseudorotation is challenging. The most direct method is to use two-dimensional infrared spectroscopy (2D-IR), and this is considered here first.

Two-Dimensional Infrared Spectroscopy. There is an excellent book on 2D-IR by Hamm and Zanni ${ }^{17}$ and a summary by Thielges and colleagues. ${ }^{18}$ The application to 
metal carbonyls has been outlined by Kubarych and colleagues, ${ }^{19}$ and a very recent review ${ }^{20}$ summarizes the experiments on metal carbonyls that have been carried out over the past few years. The literature reveals that there is often a problem relating to the difficulty of distinguishing between the effects caused by chemical exchange and those caused by intramolecular vibrational redistribution (IVR) (see ref 20 for a discussion of this). There is also a fundamental problem with the method by which 2D-IR monitors the exchange. 2D-IR requires excited vibrational states and records transitions between levels at $v=1$ in mode 1 and $v=1$ in mode 2-a point emphasized by Harris. ${ }^{11}$ The Berry mechanism, however, assumes transfer between $v=0$ states, and this point will be elaborated at a later stage.

Harris and colleagues carried out elegant 2D-IR experiments on $\mathrm{Fe}(\mathrm{CO})_{5}$ in $n$-dodecane solution. Assuming the Berry mechanism to be operational, they obtained time constants of $8.0 \pm 0.6$ ps at $18{ }^{\circ} \mathrm{C}, 6.3 \pm 0.8$ ps at $50{ }^{\circ} \mathrm{C}$, and $4.6 \pm 0.4$ ps at $90^{\circ} \mathrm{C}$, which translate into rate constant values of $1.2 \times 10^{11}$, $1.6 \times 10^{11}$, and $2.2 \times 10^{11} \mathrm{~s}^{-1}$, respectively. From an Arrhenius plot, the activation energy was calculated to be $1.6 \pm 0.3 \mathrm{kcal}$ $\mathrm{mol}^{-1}$, which is reasonably close to the range of DFT values (2.0 to $2.2 \mathrm{kcal} \mathrm{mol}^{-1}$, including Harris's value of $2.13 \mathrm{kcal}$ $\left.\mathrm{mol}^{-1}\right)$. The calculations of barrier height, however, ignore zero-point energies. The calculated zero-point energies of $D_{3 h}$ and $C_{4 v}$ structures are 25.9 and $25.8 \mathrm{kcal} \mathrm{mol}^{-1}$, respectively (BP86-D3/AE2 level, this work), meaning that the inclusion of zero-point energies would only reduce the barrier by approximately $0.1 \mathrm{kcal} \mathrm{mol}^{-1}$. In addition, Harris showed convincingly ${ }^{11}$ that the vibrational transfer was not caused by IVR.

Although 2D-IR is the most direct way of measuring the dynamics of exchange, there is in principle another method that probes the effect on band shapes in one-dimensional IR and Raman spectroscopy. This approach, analogous to the evaluation of peak behavior in NMR spectroscopy, is considered next.

One-Dimensional Infrared Spectroscopy. Spectral line shapes are a question of time scale. In order to show the effect of temperature on the spectral line shape, it is most convenient to consider the effect on NMR peaks first. If two spin $=1 / 2$ nuclei (e.g., $\left.{ }^{1} \mathrm{H}\right)$ are uncoupled and give rise to bands with a separation of $\delta \nu \mathrm{Hz}$ and a Lorentzian half-width $(1 / 2 W)$ in the absence of exchange equal to $1 / \pi T_{2}$, then with the usual Bloch equations the NMR spectrum is easily calculated as a function of the exchange rate. For the moment, just consider the extremes of "slow" (i.e., $k \rightarrow 0)$ and "fast" $(k \rightarrow \infty)$ exchange: In slow exchange, the spectrum shows two Lorentzian bands, each of which is centered at the original peak position but with half-width $(1 / 2 W)$ increased by $k / \pi$ according to $1 / 2 W / \mathrm{Hz} \approx$ $1 / \pi T_{2}+k / \pi$. However, in fast exchange, the spectrum shows only a single peak with the half-width given by $1 / 2 \mathrm{~W} / \mathrm{Hz} \approx 1$ / $\pi T_{2}+(\pi / 2 k)(\delta \nu)^{2}$. If $T_{2}=0.5 \mathrm{~s}$ and $\delta \nu=20 \mathrm{~Hz}$, then the line width can be estimated as $1 / 2 W \approx 0.64 \mathrm{~Hz}+630 / k$ for fast exchange. Thus, with $k$ values in the range $10^{3}$ to $10^{4} \mathrm{~s}^{-1}$, there is one band with a width of $1 / 2 W \approx 1.3$ to $0.7 \mathrm{~Hz}$, which shows, as is well-known, that in this regime the single coalesced band narrows with increasing $k$.

For IR and Raman spectroscopies, the following can be stated: Suppose there are two bands, $10 \mathrm{~cm}^{-1}$ apart, each with $1 / 2 W=1.0 \mathrm{~cm}^{-1}$. Assuming (for the moment) that the Bloch equations apply, one can estimate from the above relationships the magnitude of $k$ to produce coalescence. If $k=10^{10} \mathrm{~s}^{-1}$, then

the slow regime applies, and the spectrum shows two bands, each broadened by $0.1 \mathrm{~cm}^{-1}$. If $k=10^{13} \mathrm{~s}^{-1}$, the fast regime applies, and there is only a single Lorentzian profile with a width of $1 / 2 W \approx 1.5 \mathrm{~cm}^{-1}$. In order to observe dynamic effects in IR and Raman spectra, a very high exchange rate is required (on the NMR time scale, coalescence typically occurs at $k=$ $10^{4} \mathrm{~s}^{-1}$, but for IR bands, each would be broadened by a mere $10^{-7} \mathrm{~cm}^{-1}$ - an effect completely unobservable with current experimental apparatus).

However, an important point that has been emphasized in several publications (see ref 20 and literature cited therein) is that as the rate increases, there is increasing intensity at the midpoint between two absorption bands, greater than that due to the change in width of the overlapping Lorentzian profiles. Indeed, in the early days of NMR spectroscopy, before the advent of dynamic NMR computer programs, this extra intensity buildup was used to estimate exchange rates. ${ }^{21}$

The coalescence effect in vibrational spectra is wellillustrated in experiments by Kim and Hochstrasser, ${ }^{22}$ who investigated the equilibrium between free $\mathrm{CH}_{3} \mathrm{CN}$ ( $\mathrm{C}-\mathrm{N}$ stretch at $\left.2254 \mathrm{~cm}^{-1}\right)$ and $\mathrm{H}$-bonded $\mathrm{CH}_{3} \mathrm{CN}\left(2263 \mathrm{~cm}^{-1}\right)$ in methanol solution. These experiments are also significant because the authors compare the FTIR data with data from 2D-IR experiments; the kinetic results are similar. The first evidence for this type of behavior in metal carbonyls was obtained by Grevels and co-workers ${ }^{23,24}$ during studies of the $\nu(\mathrm{CO})$ absorption bands in the IR spectra of iron(tricarbonyl)diene complexes, $\mathrm{Fe}(\mathrm{CO})_{3}$ (diene) (see Figure 7).

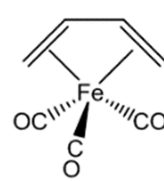

$\mathrm{Fe}(\mathrm{CO})_{3}(\mathrm{BUT})$

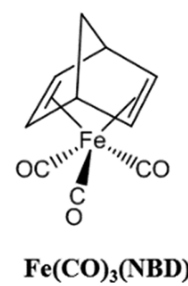

$\mathrm{Fe}(\mathrm{CO})_{3}(\mathrm{NBD})$

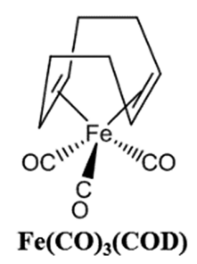

Figure 7. $\mathrm{Fe}(\mathrm{CO})_{3}$ (diene) complexes showing rapid $\mathrm{CO}$ ligand scrambling; diene refers to butadiene (BUT), norbornadiene (NBD), and cyclooctadiene (COD).

On the basis of ${ }^{13} \mathrm{C} \mathrm{NMR}$ data, ${ }^{25}$ the barrier to turnstile rotation in $\mathrm{Fe}(\mathrm{CO})_{3}(\mathrm{BUT})$ was determined to be $8 \mathrm{kcal} \mathrm{mol}^{-1}$, which results in an exchange rate that is much too low to have any effect on the vibrational spectrum. However, Fe$(\mathrm{CO})_{3}(\mathrm{NBD})$ and $\mathrm{Fe}(\mathrm{CO})_{3}(\mathrm{COD})$ behave like $\mathrm{Fe}(\mathrm{CO})_{5}$ in that the ${ }^{13} \mathrm{C}$ NMR spectra show only a single peak for the three carbonyl ligands at all accessible temperatures. Figure 8a displays the change ${ }^{26}$ in the IR spectrum of $\mathrm{Fe}(\mathrm{CO})_{3}(\mathrm{COD})$ in 2-methylpentane in the $\nu(\mathrm{CO})$ region.

The two low-frequency bands, assigned to the symmetry species $\mathrm{a}^{\prime}$ and $\mathrm{a}^{\prime \prime}$ of the $C_{s}$ point group, merge as the temperature is raised. Grevels reasoned that if the $\mathrm{CO}$ groups rotate very fast, then the complex effectively adopts $C_{3 v}$ symmetry and the $\mathrm{a}^{\prime}$ and $\mathrm{a}^{\prime \prime}$ vibrations become $\mathrm{e}^{\prime}$. However, before kinetic data can be extracted from coalescing IR spectra, there are several problems to be resolved that concern the Bloch equations, line shapes, and the relationship between vibrations and torsional energy levels.

The Bloch Equations. Considerable doubt has been cast on the use of the Bloch method for vibrational spectra, particularly by Strauss ${ }^{27-29}$. Grevels was well aware of this question in his first publications ${ }^{23,24}$ but assumed that one 


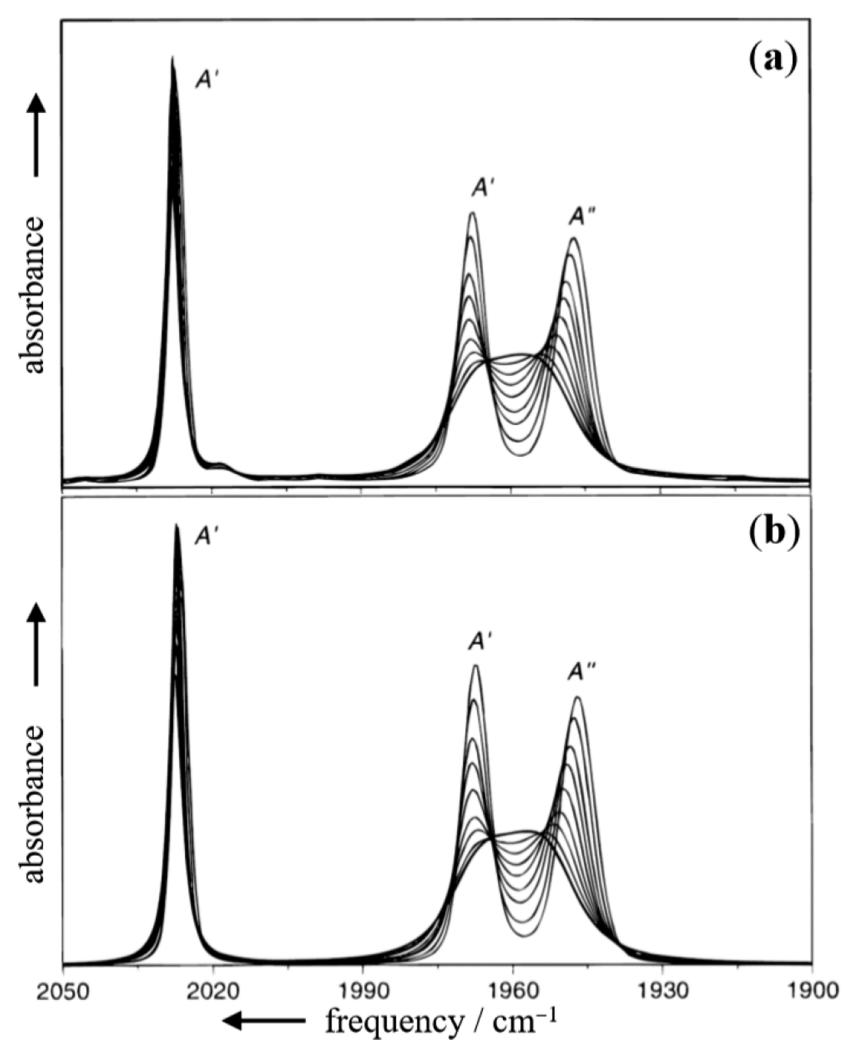

Figure 8. $\nu(\mathrm{CO})$ bands of the variable-temperature spectra of $\mathrm{Fe}(\mathrm{CO})_{3}(\mathrm{COD})$ in 2-methylpentane solution between 133 and 293 $\mathrm{K}$ : (a) observed; (b) simulated assuming rapid $\mathrm{CO}$ site exchange. Reproduced with permission from ref 26. Copyright 1998 American Chemical Society.

could obtain reasonable values for rate constants and barrier heights. This point has been much discussed, and the details were summarized by us elsewhere. ${ }^{20}$ The general conclusion is that the method is applicable, but one must be cautious when trying to extract accurate data. In fact, two educational publications ${ }^{30,31}$ show advanced students how to obtain kinetic data from the coalescing $\nu(\mathrm{CO})$ bands of $\mathrm{Fe}(\mathrm{CO})_{3}(\mathrm{COD})$.

Lorentzian Shapes. So far, the discussion has assumed Lorentzian shapes for the absorption bands. Of course, IR bands almost always show a convolution of Lorentz and Gaussian functions. This can be accommodated by employing Voigt functions.

Frequencies and Half-Widths of IR Bands without Exchange. The application of the Bloch equations assumes that the positions and half-widths of the bands in the absence of exchange do not alter with a change in conditions, i.e., as the temperature is raised. For NMR spectra this is true, but as is well-known, for IR and Raman spectra these can vary dramatically depending on the solvent. Thus, it is necessary to include such considerations carefully in any analysis.

Contribution from Torsional Energy Levels. It was pointed out by Strauss ${ }^{29}$ that if the torsional barrier vibrational levels are populated and if the anharmonic coupling between these vibrations and the $\nu(\mathrm{CO})$ stretching vibrations is significant, then the latter may be affected as the temperature is raised without any reference to exchange. This would make the Grevels approach invalid. Fortunately, for the iron tricarbonyl species, DFT calculations show that the $\nu(\mathrm{CO})$ vibrations are hardly affected as the barrier is climbed. ${ }^{20}$ This point is raised here because it is important to consider such effects in the case of $\mathrm{Fe}(\mathrm{CO})_{5}$, and this will be discussed later.

Interacting Vibrations. For metal carbonyls, there is mixing of the $\mathrm{C}-\mathrm{O}$ stretching vibrations, which greatly complicates the issue. In the paper by Grevels et al., ${ }^{26}$ McClung showed the method of taking this into account, and the net result is shown in Figure $8 \mathrm{~b}$. The match between experiment (Figure 8a) and theory (Figure $8 \mathrm{~b}$ ) is impressive. It is important, for comparison with $\mathrm{Fe}(\mathrm{CO})_{5}$, to see how this was done. The starting point was to assume that in the absence of exchange, the $\nu(\mathrm{CO})$ band positions shifted slightly with temperature in a manner similar to the nonexchanging $\mathrm{Fe}(\mathrm{CO})_{3}(\mathrm{BUT})$. McClung's spectrum simulation program was then used to fit the spectra at different temperatures with changing values of the rate constant. The details of the mathematical apparatus are given in the SI. The rate varied from $1.5 \times 10^{11} \mathrm{~s}^{-1}$ at $133 \mathrm{~K}$ to $1.54 \times 10^{12} \mathrm{~s}^{-1}$ at $293 \mathrm{~K}$. An Arrhenius plot gave a straight line with an activation energy of $1.1 \mathrm{kcal} \mathrm{mol}^{-1}$. The McClung program generates nonexchanging Voigt profiles for the coalescing bands; see Table 3 in ref 26. For example, the nonexchanging half-widths $w_{\mathrm{G}}$ (Gaussian) and $w_{\mathrm{L}}$ (Lorentzian) of the a" band at $\sim 1948 \mathrm{~cm}^{-1}$ are 6.8 and $0.9 \mathrm{~cm}^{-1}$, respectively, at $133 \mathrm{~K}$ and 1.2 and $5.6 \mathrm{~cm}^{-1}$, respectively, at $293 \mathrm{~K}$.

In several elegant experiments, Lear and co-workers ${ }^{32-34}$ extended these experiments and essentially confirmed Grevels's conclusions. It is worth mentioning that two authors ${ }^{30,32}$ have suggested a mistake in McClung's method, but a careful analysis of the mathematics shows that the supposed error is due only to an unconventional definition and that in fact McClung's method is essentially the same as theirs.

Behavior of $\mathrm{Fe}(\mathrm{CO})_{5}$. What might one expect to observe for a rapid exchange in $\mathrm{Fe}(\mathrm{CO})_{5}$ ? Compared with the dienes, there is no obvious point-group symmetry to assign to a rapidly exchanging five-coordinate system. However, it is straightforward to extend the $(\mathrm{CO})_{3}$ McClung method to a $(\mathrm{CO})_{5}$ exchanging system, and McClung has provided the appropriate modification of the method. We are greatly indebted to him. Figure 9 shows the expected pattern as the rate of the Berry pseudorotation increases.

Not surprisingly, the predicted pattern shows coalescence to a single band and mimics NMR behavior. It is clear that there is a buildup of intensity between the peaks before there is clear moving-together of the peaks. The importance of this extra intensity feature has been mentioned above.

In addition to their 2D-IR work, Harris and colleagues ${ }^{11}$ also carefully examined the FTIR spectra of $\mathrm{Fe}(\mathrm{CO})_{5}$ in $n$ dodecane as a function of temperature and concluded that although there were hints of coalescence-including some evidence for buildup of interpeak intensity - it was not possible to distinguish satisfactorily between a broadening pair of Lorentzian profiles and the effect of exchange based on McClung's approach (see the SI). Attempts to extract kinetic data were not really successful, with rate constants "on the order of $0.1 \mathrm{ps}^{-1}$ ", compared with 0.12 to $0.22 \mathrm{ps}^{-1}$ from their 2D-IR measurements. The real problem is that before there is convincing evidence of coalescence with increasing temperature, $\mathrm{Fe}(\mathrm{CO})_{5}$ decomposes. However, with the advantage of liquid $\mathrm{Xe}$ as a solvent and the resultant very high quality FTIR spectra, we believe that there is weak but clear evidence for the buildup of intensity between the peaks, which becomes clearly apparent by comparison of spectra at low and high temperature 


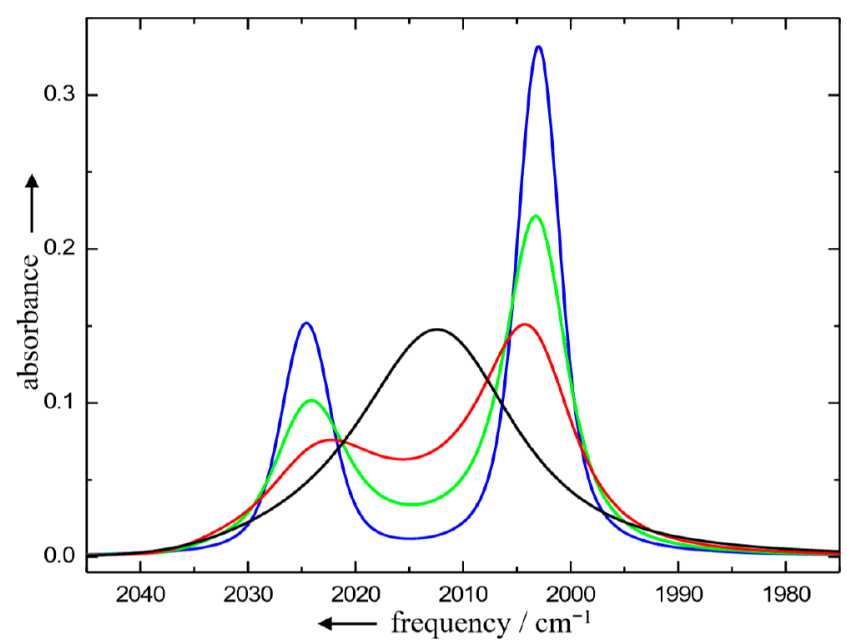

Figure 9. Simulated IR absorption spectra of $\mathrm{Fe}(\mathrm{CO})_{5}$ in the region of the $\nu(\mathrm{CO})$ stretching vibrations. The simulation is based on the model of a Berry pseudorotation using the exchange rate constants $k_{\text {exch }} / \mathrm{s}^{-1}=0$ (blue), $3.17 \times 10^{11}$ (green), $8.17 \times 10^{11}(\mathrm{red})$, and 3.17 $\times 10^{12}$ (black). The band maxima 2024.57 and $2002.98 \mathrm{~cm}^{-1}$ and widths $w_{\mathrm{L}} / \mathrm{cm}^{-1}=2.58,3.95$ and $w_{\mathrm{G}} / \mathrm{cm}^{-1}=2.75,3.08$ apply throughout $(\mathrm{L}=$ Lorentzian; $\mathrm{G}=$ Gaussian $)$.

with the spectral shape predicted using two pseudo-Voigt profiles (Figure 10).

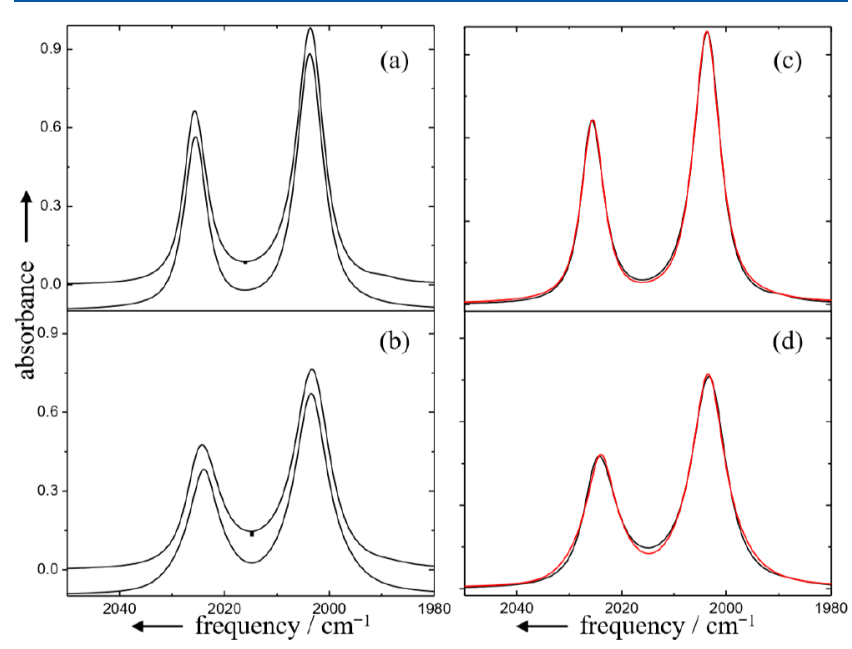

Figure 10. The $\mathrm{a}_{2}{ }^{\prime \prime}$ and $\mathrm{e}^{\prime}$ bands (ca. 2025 and $2003 \mathrm{~cm}^{-1}$ ) of a $\mathrm{Fe}(\mathrm{CO})_{5}$ solution in supercritical Xe $\left(14.67 \mathrm{~mol} \mathrm{dm}^{-3}\right)$ at $(\mathrm{a}, \mathrm{c}) 301.6$ $\mathrm{K}$ (2054 psi) and (b, d) $386.1 \mathrm{~K}$ (6372 psi). (left) Simulated spectra based on the best fit using two pseudo-Voigt profiles offset 0.1 au below experimental spectra. Thick black lines (I) indicate the extra intensity in the experimental spectra, greater than that predicted on the basis of simple band overlap. (right) Experimental (black) and simulated (red) spectra shown without offset. The areas under the experimental spectra are normalized.

But can one obtain quantitative data? Figure 11 shows a whole range of IR spectra of $\mathrm{Fe}(\mathrm{CO})_{5}$ in supercritical xenon as a function of temperature. It was noticed that band maxima shift less and bands broaden less with increasing temperature when the density of the supercritical fluid is kept constant instead of the pressure of the fluid (see Table S1).

Starting with the same assumptions as employed for COD, the IR spectra of $\mathrm{Fe}(\mathrm{CO})_{5}$ were simulated which resulted in the data shown in Table 3. Figure 12 shows an Arrhenius plot

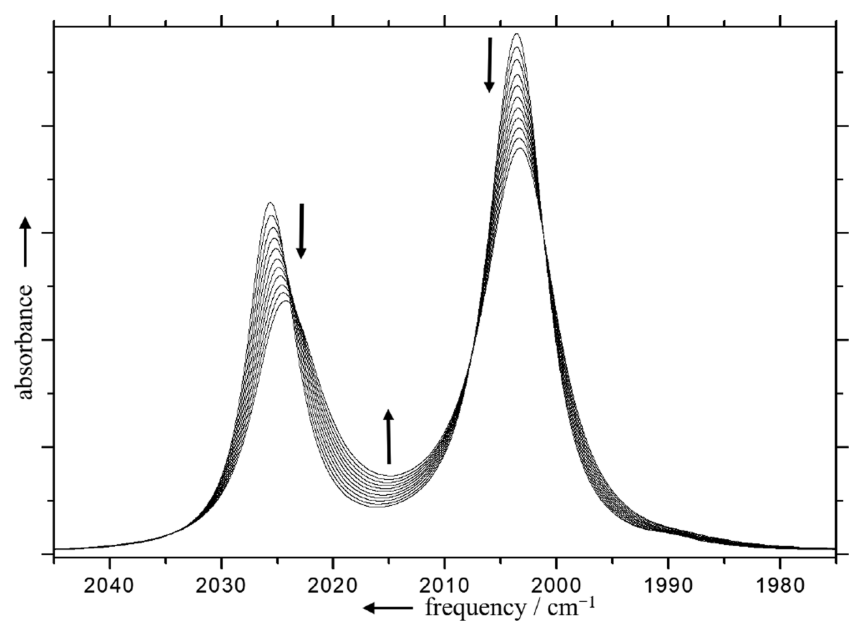

Figure 11. The $1975-2045 \mathrm{~cm}^{-1}$ section of the temperaturedependent IR spectra of $\mathrm{Fe}(\mathrm{CO})_{5}$ in supercritical xenon in the temperature interval 302 to $386 \mathrm{~K}$ recorded at an optical resolution of $0.5 \mathrm{~cm}^{-1}$.

derived from these data. Given the difficulties of the measurements, the data adhere to a pleasing straight line within the estimated margins of error. The experimentally determined Arrhenius activation energy was found to be $E_{\mathrm{a}}=$ $2.5 \pm 0.4 \mathrm{kcal} \mathrm{mol}^{-1}$. This is in remarkable agreement with the DFT-calculated values ranging from 2.0 to $2.3 \mathrm{kcal} \mathrm{mol}^{-1}$ and is encouraging for the one-dimensional IR technique. The corresponding values of $\Delta H^{\ddagger} /\left(\mathrm{kcal} \mathrm{mol}^{-1}\right)$ and $\Delta G^{\ddagger} /(\mathrm{kcal}$ $\mathrm{mol}^{-1}$ ) are $1.8 \pm 0.4$ and $3.9 \pm 1.6$ (experiment) and 1.4 and 3.2 (theory, DFT; see Table 2). The activation energy obtained from the $2 \mathrm{D}$-IR experiments ${ }^{11}$ was $1.6 \pm 0.3 \mathrm{kcal}$ $\mathrm{mol}^{-1}$. The differing experimental values could possibly arise from two factors: ( $i$ ) as mentioned above, 2D-IR supplies kinetic data between excited vibrational states, and (ii) the solvent, $n$-dodecane in this case, might influence the kinetics. We have therefore been investigating the interaction between $\mathrm{Fe}(\mathrm{CO})_{5}$ and various solvents as an extension of the RosePetruck work, ${ }^{13}$ and this will be published shortly. However, there are further structural dynamics implications to consider.

DFT calculations ${ }^{20}$ of the $\mathrm{Fe}(\mathrm{CO})_{3}$ (diene) complexes (Figure 7) show that as the barrier is climbed, both lowfrequency bands ( $a^{\prime}$ and $a^{\prime \prime}$ ) hardly shift. This means that any extra intensity between peaks must be produced by exchange. With $\mathrm{Fe}(\mathrm{CO})_{5}$, the observations are different. Because of the change in symmetry in going from the ground state $\left(D_{3 h}\right)$ to the transition state $\left(C_{4 v}\right)$ via $C_{2 v}$ structures, the spectra are quite complex and change as the barrier is climbed. Calculations were therefore carried out for $\mathrm{Fe}(\mathrm{CO})_{5}$ free of solvent-solute interactions. The key spectral parameters as a function of the energy change as the barrier is climbed are shown in Table $4 .^{36}$

The calculations resulted in a ground state showing the expected two IR-active bands ( $\mathrm{e}^{\prime}$ and $\mathrm{a}_{2}^{\prime \prime}$ ) at 2008 and 2023 $\mathrm{cm}^{-1}$, respectively, with an intensity ratio of $1910 / 1129$, and two IR-inactive bands $\left(a^{\prime}\right)$, which compare well with experimental values in $\mathrm{Xe}\left(\mathrm{e}^{\prime}, 2000 \mathrm{~cm}^{-1}\right.$ and $\mathrm{a}_{2}^{\prime \prime}, 2024$ $\left.\mathrm{cm}^{-1}\right)$. The calculations indicate that as the barrier is climbed and the symmetry changes from $D_{3 h}$ through $C_{2 v}$ to $C_{4 v}$ at the transition state, a considerable number of new bands should appear, provided that the Kubo parameter remains high $(k \gg$ 
Table 3. Band Parameters $\left(\nu, w_{\mathrm{L}}, w_{\mathrm{G}}, w\right)^{a}$ and Rate Constants $\left(k_{\mathrm{exch}}\right)$ after Curve Fitting Using the Berry Model of Pseudorotation in the Temperature-Dependent IR Spectra of $\mathrm{Fe}(\mathrm{CO})_{5}$ at Various Temperatures $(T)$ in Supercritical Xenon at Constant Density ${ }^{c}$

\begin{tabular}{|c|c|c|c|c|c|c|c|c|c|}
\hline$T / \mathrm{K}$ & $\nu\left(\mathrm{e}^{\prime}\right) / \mathrm{cm}^{-1}$ & $w_{\mathrm{L}} / \mathrm{cm}^{-1}$ & $w_{\mathrm{G}} / \mathrm{cm}^{-1}$ & $w_{\mathrm{V}} / \mathrm{cm}^{-1 b}$ & $\nu\left(\mathrm{a}_{2}{ }^{\prime \prime}\right) / \mathrm{cm}^{-1}$ & $w_{\mathrm{L}} / \mathrm{cm}^{-1}$ & $w_{\mathrm{G}} / \mathrm{cm}^{-1}$ & $w_{\mathrm{V}} / \mathrm{cm}^{-1 b}$ & $k_{\text {exch }} /\left(10^{11} \mathrm{~s}^{-1}\right)$ \\
\hline $301.6(5)$ & $2003.56(1)$ & $3.91(22)$ & $2.55(12)$ & 4.77 & $2025.68(2)$ & $2.89(25)$ & $2.09(8)$ & 4.04 & $1.26(20)$ \\
\hline $309.7(5)$ & $2003.53(2)$ & $3.89(17)$ & $2.59(12)$ & 4.80 & $2025.58(2)$ & $2.88(18)$ & $2.11(7)$ & 4.04 & $1.45(18)$ \\
\hline $318.3(5)$ & $2003.48(2)$ & $3.88(15)$ & $2.64(11)$ & 4.84 & $2025.48(2)$ & $2.87(17)$ & $2.13(8)$ & 4.04 & $1.64(18)$ \\
\hline $326.8(5)$ & $2003.43(2)$ & $3.87(16)$ & $2.71(6)$ & 4.91 & $2025.37(2)$ & $2.88(14)$ & $2.13(10)$ & 4.06 & $1.84(17)$ \\
\hline $334.0(5)$ & $2003.38(2)$ & $3.86(15)$ & $2.78(6)$ & 4.97 & $2025.26(3)$ & $2.91(12)$ & $2.16(11)$ & 4.10 & $1.99(17)$ \\
\hline $343.3(5)$ & $2003.32(2)$ & $3.82(10)$ & $2.86(4)$ & 5.01 & $2025.15(2)$ & $2.92(6)$ & $2.18(9)$ & 4.12 & $2.19(14)$ \\
\hline $351.5(5)$ & $2003.26(2)$ & $3.85(10)$ & $2.90(6)$ & 5.08 & $2025.04(3)$ & $2.93(6)$ & $2.18(9)$ & 4.13 & $2.37(14)$ \\
\hline $359.5(5)$ & $2003.20(2)$ & $3.82(5)$ & $2.97(6)$ & 5.13 & $2024.93(3)$ & $2.92(3)$ & $2.18(7)$ & 4.12 & $2.56(12)$ \\
\hline $368.0(5)$ & $2003.13(2)$ & $3.82(6)$ & $3.03(7)$ & 5.18 & $2024.81(3)$ & $2.95(5)$ & $2.18(3)$ & 4.15 & $2.74(11)$ \\
\hline $376.4(5)$ & $2003.04(2)$ & $3.78(8)$ & $3.17(9)$ & 5.29 & $2024.68(3)$ & $2.94(7)$ & $2.25(8)$ & 4.18 & $2.93(12)$ \\
\hline $386.0(5)$ & $2002.97(2)$ & $3.79(8)$ & $3.23(7)$ & 5.36 & $2024.56(3)$ & $2.98(12)$ & $2.21(4)$ & 4.19 & $3.15(13)$ \\
\hline
\end{tabular}

${ }^{a} \nu$ is the band position, and $w_{\mathrm{L}}$ and $w_{\mathrm{G}}$ are the Lorentzian and Gaussian contributions, respectively, to the full width at half-maximum of the Voigt profile $\left(w_{\mathrm{V}}\right) .{ }^{b} w_{\mathrm{V}}$ was approximated as $0.5346 w_{\mathrm{L}}+\left(0.2166 w_{\mathrm{L}}{ }^{2}+w_{\mathrm{G}}{ }^{2}\right)^{0.5}$ (see ref 35). ${ }^{c}$ Estimated uncertainties are given in parentheses.

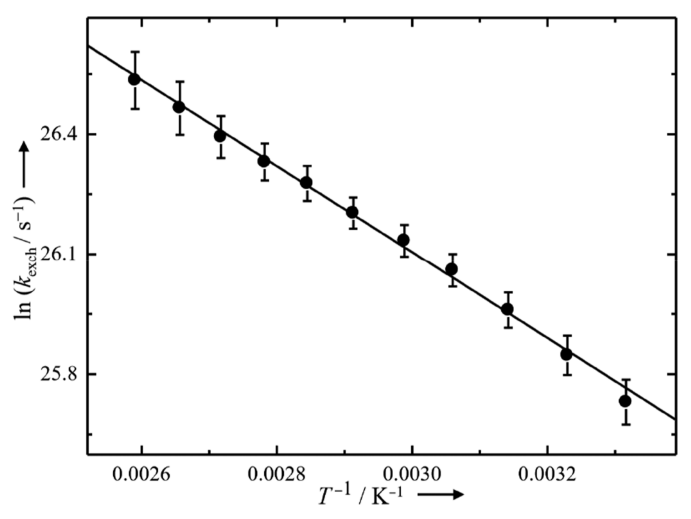

Figure 12. Arrhenius plot based on the data given in Table 3. The error bars relate to the uncertainty of $k_{\text {exch }}$ over the course of three to four repetitions of curve fitting at individual temperatures.

$0)$. The relevance of the Kubo parameter is well-described in papers by Strauss and colleagues. ${ }^{27-29}$

The intensities of these bands will increase with the temperature. For instance, in the regions between the ground and transition states, there are bands calculated to lie roughly halfway between the experimentally observed bands in the spectral region between ca. 2014 and $2017 \mathrm{~cm}^{-1}$. As the temperature is raised, these bands are predicted to make an increasing but still very small contribution to the spectrum, and this could in principle add extra intensity between the main peaks and hence make the kinetic interpretation invalid. However, there are two reasons for rejecting this model. In the first place, the Kubo parameters for the vibrational levels in these carbonyls have values $k \ll 0$, which implies that the molecule is very rapidly switching among the torsional levels. The resulting spectra are not the sum of contributing spectra but the intensity-weighted average of the spectra. (For a discussion of this point, see ref 20.) Second, if this were a determining factor, the rate constants would be way out of line, and the activation energy would not be sensible.

Spectra of Isotopic $\mathrm{Fe}(\mathrm{CO})_{5}$. The exchange between ax$\mathrm{Fe}\left({ }^{13} \mathrm{CO}\right)\left({ }^{12} \mathrm{CO}\right)_{4}$ and eq- $\mathrm{Fe}\left({ }^{13} \mathrm{CO}\right)\left({ }^{12} \mathrm{CO}\right)_{4}$ isotopomers will mimic the behavior of their isotopologue, $\mathrm{Fe}\left({ }^{12} \mathrm{CO}\right)_{5}$. In principle, it should therefore be possible to examine the $\nu(\mathrm{CO})$ absorption bands of the isotopic molecules for similar behavior. Bands 5 and 6 in Figures 3 and 5 are assigned to the axial and equatorial isotopomers. Moreover, because they

Table 4. Relative Energies $\left(E_{\text {rel, }}\right.$ in $\left.\mathrm{kcal} \mathrm{mol}^{-1}\right)$ and CO Stretching Frequencies in $\mathrm{Fe}(\mathrm{CO})_{5}$ Calculated at the BP86/AE1 Level along the Intrinsic Reaction Coordinate (IRC, in $\mathbf{a m u}^{1 / 2}$ bohr)

\begin{tabular}{|l|l|l|l|l|l|l|}
\hline IRC & $E_{\text {rel }}$ & \multicolumn{4}{l|}{ Frequencies, Symmetry species and Intensities ${ }^{a}$} \\
\hline Ground State & 0.0 & $\mathbf{2 0 0 8} e^{\prime} / 1910$ & $\mathbf{2 0 2 3} a_{2}{ }^{\prime} / 1129$ & $2028 a_{1}^{\prime} / 0$ & $\mathbf{2 0 9 8} a_{1}^{\prime} / 0$ \\
\hline 0.35 & 0.03 & $\mathbf{2 0 0 8} b_{2} / 978$ & $\mathbf{2 0 0 9} a_{1} / 927$ & $\mathbf{2 0 2 4} b_{1} / 1129$ & $\mathbf{2 0 2 8} a_{1} / 4$ & $\mathbf{2 0 9 8} a_{1} / 0$ \\
\hline 0.30 & 0.24 & $\mathbf{2 0 0 7} b_{2} / 1016$ & $\mathbf{2 0 1 0} a_{1} / 854$ & $\mathbf{2 0 2 3} b_{1} / 1128$ & $2028 a_{1} / 36$ & $\mathbf{2 0 9 8} a_{1} / 0$ \\
\hline 0.25 & 0.62 & $\mathbf{2 0 0 6} b_{2} / 1047$ & $\mathbf{2 0 1 1} a_{1} / 761$ & $\mathbf{2 0 2 2} b_{1} / 1127$ & $2028 a_{1} / 93$ & $\mathbf{2 0 9 8} a_{1} / 0$ \\
\hline 0.20 & 1.08 & $\mathbf{2 0 0 6} b_{2} / 1071$ & $\mathbf{2 0 1 3} a_{1} / 659$ & $\mathbf{2 0 2 1} b_{1} / 1128$ & $2027 a_{1} / 164$ & $\mathbf{2 0 9 7} a_{1} / 0$ \\
\hline 0.15 & 1.52 & $\mathbf{2 0 0 7} b_{2} / 1090$ & $\mathbf{2 0 1 5} a_{1} / 550$ & $\mathbf{2 0 1 9} b_{1} / 1127$ & $2026 a_{1} / 247$ & $\mathbf{2 0 9 7} a_{1} / 0$ \\
\hline 0.10 & 1.91 & $\mathbf{2 0 0 8} b_{2} / 1104$ & $\mathbf{2 0 1 7} b_{1} / 1126$ & $\mathbf{2 0 1 7} a_{1} / 425$ & $\mathbf{2 0 2 5} a_{1} / 352$ & $\mathbf{2 0 9 6} a_{1} / 0$ \\
\hline 0.05 & 2.15 & $\mathbf{2 0 1 0} b_{2} / 1114$ & $\mathbf{2 0 1 4} b_{1} / 1125$ & $\mathbf{2 0 1 9} a_{1} / 253$ & $2024 a_{1} / 512$ & $\mathbf{2 0 9 6} a_{1} / 0$ \\
\hline Transition State & 2.24 & $\mathbf{2 0 1 2} e / 1121$ & $\mathbf{2 0 2 0} b_{2} / 0$ & $2023 a_{1} / 761$ & $\mathbf{2 0 9 6} a_{1} / 1$ \\
\hline
\end{tabular}

${ }^{a}$ Harmonic vibrational frequencies (in $\mathrm{cm}^{-1}$ ) are shown in bold type, followed by the symmetry labels of the vibrations (in the $D_{3 h}, C_{2 v}$, and $C_{4 v}$ point groups for ground, intermediate, and transition states, respectively)/IR intensities (in $\mathrm{km} \mathrm{mol}^{-1}$ ) in normal type. A color code applies to the various vibrational modes to guide the eye. It should be noted that depending on the point-group symmetry, corresponding vibrations can have different symmetry labels. 
are closer in frequency than the main $\nu(\mathrm{CO})$ absorption bands of $\mathrm{Fe}\left({ }^{12} \mathrm{CO}\right)_{5}$, they should display this behavior more obviously. Figure 4 shows this phenomenon to occur in 2methylpentane, where the bands appear to be coalescing. Disappointingly, although there is some evidence for band coalescence in $\mathrm{Xe}$, it is not convincing, and it is certainly not sufficient to produce meaningful kinetic data.

\section{EXPERIMENTAL SECTION}

Spectroscopy. The variable-temperature experiments involving $\mathrm{Fe}(\mathrm{CO})_{5}$ in xenon were carried out at the School of Chemistry of the University of Nottingham. Spectra in 2-methylcyclohexane and krypton were recorded by Grevels and Klotzbücher at the MaxPlanck-Institut für Bioanorganische Chemie. Fourier transform infrared spectra were recorded at a resolution of $0.5 \mathrm{~cm}^{-1}$ using custom-made miniature high-pressure stainless steel (r.t. to $386 \mathrm{~K}$ ) and annealed copper ( 162 to $316 \mathrm{~K}$ ) optical cells, which were adapted from published designs and equipped with $\mathrm{CaF}_{2}$ windows of various thicknesses. ${ }^{37}$ For measurements at and above the critical point, a constant density of xenon $\left(14.7 \mathrm{~mol} \mathrm{dm}{ }^{-3}\right)$ was maintained in the spectroscopic cell. The high-pressure stainless steel gas handling manifold and the optical cells connected to it were deoxygenated prior to loading of samples and preparation of solutions. After each temperature change and before each spectral measurement, the optical cells were allowed to equilibrate for $20 \mathrm{~min}$, after which the temperature in solution was constant to within $\pm 0.2 \mathrm{~K}$. No sample degradation was observed below ca. $383 \mathrm{~K}$. Measurements at low temperature were performed using an annealed $\mathrm{Cu}$ cell mounted on a cold finger cooled by a Displex He closed-cycle cryostat and protected by a high-vacuum shroud equipped with $\mathrm{CaF}_{2}$ windows. Solutions were prepared with $\mathrm{Fe}(\mathrm{CO})_{5}$ concentrations on the order of $10^{-3} \mathrm{~mol}$ $\mathrm{dm}^{-3}$, and the $\nu(\mathrm{CO})$ absorption band maxima were kept below unity.

Computations. Geometries were optimized at the BP86 and BP86-D3 levels of DFT (the latter including Grimme's empirical dispersion correction), employing the following basis sets: AE1, an augmented $(8 \mathrm{~s} 7 \mathrm{p} 4 \mathrm{~d})$ Wachters' basis on $\mathrm{Fe}$ and the $6-31 \mathrm{G}(\mathrm{d})$ basis on $\mathrm{C}$ and $\mathrm{O}$; AE2, the same Wachters' basis on Fe, the aug-cc-pVTZPP basis together with the Stuttgart-Köln RSC-28-MDF relativistic effective core potential on $\mathrm{Xe}$ and the $6-311+\mathrm{G}(\mathrm{d}, \mathrm{p})$ basis on $\mathrm{C}$ and O. Starting from the BP86/AE1 transition state for $\mathrm{Fe}(\mathrm{CO})_{5}$, the intrinsic reaction coordinate (IRC) was followed. Harmonic frequencies were computed analytically for the stationary points as well as for selected points on the IRC and are reported without scaling. Energies and frequencies for $\mathrm{Fe}(\mathrm{CO})_{5} \cdots \mathrm{Xe}$ were corrected for basis-set superposition error (BSSE) using the counterpoise method. The BP86-D3/AE2 frequencies were also used to calculate zero-point energies and thermodynamic corrections to enthalpies and free energies at $298 \mathrm{~K}$. The scan in Figure 6 was obtained by fixing the $\mathrm{Fe} \cdots \mathrm{Xe}$ distance at selected values and relaxing all of the other parameters at the BP86-D3/AE2 level (including BSSE correction); the BP86/AE2 data were obtained by subtracting the -D3 correction from the BP86-D3/AE2 energies at each of the optimized points. These computations employed the Gaussian suite of programs. See the SI for full details and references.

\section{CONCLUSION}

On the basis of temperature-dependent FTIR spectral measurements in supercritical xenon solution at a constant density, a reliable value of $2.5 \pm 0.4 \mathrm{kcal} \mathrm{mol}^{-1}$ has been obtained for the activation energy of the intramolecular interchange of $\mathrm{CO}$ ligands in $\mathrm{Fe}(\mathrm{CO})_{5}$ according to the Berry pseudorotation mechanism. This was enabled by a quantitative line shape analysis that accounts for the exchangerate-dependent changes in the absorption bands of the $\mathrm{CO}$ stretching vibrations. The fluxionality of $\mathrm{Fe}(\mathrm{CO})_{5}$ was investigated by DFT calculations, which afforded an activation barrier for pseudorotation that is consistent with the experimental value. A solvate-assisted mechanism in the supercritical xenon fluid is unlikely, since any possible $\mathrm{Xe}-$ Fe coordination is of a weak van der Waals-type that leads to an only marginally lower activation barrier.

\section{ASSOCIATED CONTENT}

\section{S Supporting Information}

The Supporting Information is available free of charge on the ACS Publications website at DOI: 10.1021/acs.organomet.9b00559. Research data supporting this publication can be accessed at https://doi.org/10.17630/2b3d2f0e-7add-46e09b2e-db94fbbbc0e1.

Energy-factored force field for metal carbonyls, details on the computer program for the evaluation of the energy-factored $\mathrm{CO}$ force field parameters, the eigenvector matrix, the wavenumbers of individual $\mathrm{CO}$ stretching vibrations, exchange and $z$ matrices, coordinates, further computational details, and details of spectral measurements and sample preparation (PDF)

Coordinate file (XYZ)

\section{AUTHOR INFORMATION}

\section{Corresponding Author}

*E-mail: p.portius@sheffield.ac.uk.

ORCID

Peter Portius: 0000-0001-8133-8860

Michael W. George: 0000-0002-7844-1696

\section{Author Contributions}

F.-W.G. initiated the research and contributed the initial force field analysis. M.B. performed the DFT calculations. P.P. performed the experimental studies. P.P. and J.J.T. analyzed the data and wrote the manuscript with the help of all authors.

\section{Notes}

The authors declare no competing financial interest.

${ }^{\#}$ F.-W.G.: deceased in 2016.

\section{ACKNOWLEDGMENTS}

The authors are indebted to Prof. T. E. D. McClung (University of Alberta at Edmonton) and Dr. W. E. Klotzbücher (Max-Planck-Institut für Bioanorganische Chemie, Mülheim an der Ruhr) for the provision of the IR spectrum simulation program for fluxional carbonyl complexes and the indicated spectral data (Figure ${ }^{5, a}$ ). M.B. thanks the School of Chemistry and EaStCHEM for support. Calculations were performed on a local Opteron cluster maintained by Dr. H. Fruchtl. P.P. thanks the School of Chemistry, University of Nottingham, and the European Commission's 6th Framework Programme (Grant 502440) for supporting the experimental work.

\section{ABBREVIATIONS}

BUT, butadiene; COD, cyclooctadiene; DFT, density functional theory; FTIR, Fourier transform infrared; IVR, intramolecular vibrational redistribution; NBD, norbornadiene; NMR, nuclear magnetic resonance.

\section{REFERENCES}

(1) Mond, L.; Quincke, F. Note on a Volatile Compound of Iron with Carbonic Oxide. J. Chem. Soc., Trans. 1891, 59, 604-607. 
(2) Beagley, B.; Schmidling, D. G. A Re-Evaluation of the Molecular Structure of Iron Pentacarbonyl. J. Mol. Struct. 1974, 22, 466-468.

(3) Cotton, F. A.; Danti, A.; Waugh, J. S.; Fessenden, R. W. Carbon13 Nuclear Resonance Spectrum and Low-Frequency Infrared Spectrum of Iron Pentacarbonyl. J. Chem. Phys. 1958, 29, 1427-1428.

(4) Jesson, J. P.; Meakin, P. Nuclear Magnetic Resonance Evidence for Stereochemical Rigidity in $\mathrm{ML}_{5}$ Complexes. J. Am. Chem. Soc. 1973, 95, 1344-1346.

(5) Sheline, R. K.; Mahnke, H. The Flipping of CO Ligand Groups in Metal Carbonyl Compounds and its Frequency in $\mathrm{Fe}(\mathrm{CO})_{5}$. Angew. Chem., Int. Ed. Engl. 1975, 14, 314-321.

(6) Berry, R. S. Correlation of Rates of Intramolecular Tunneling Processes, with Application to Some Group V Compounds. J. Chem. Phys. 1960, 32, 933-938.

(7) Spiess, H. W.; Grosescu, R.; Haeberlen, U. Molecular motion studied by NMR powder spectra. II. Experimental results for solid tetraatomic phosphorus and solid iron pentacarbonyl. Chem. Phys. 1974, 6, 226-234.

(8) Hanson, B. E.; Whitmire, K. H. Exchange of Axial and Equatorial Carbonyl Groups in Pentacoordinate Metal Carbonyls in the Solid State. The Variable Temperature Magic Angle Spinning Carbon-13 NMR spectroscopy of iron pentacarbonyl, $\left[\mathrm{Ph}_{3} \mathrm{PNPPh}_{3}\right][\mathrm{HFe}-$ $\left.(\mathrm{CO})_{4}\right]$, and $\left[\mathrm{NEt}_{4}\right]\left[\mathrm{HFe}(\mathrm{CO})_{4}\right]$. J. Am. Chem. Soc. 1990, 112, 974-977.

(9) Burdett, J. K.; Grzybowski, J. M.; Poliakoff, M.; Turner, J. J. Freezing out the fluxional behavior in iron pentacarbonyl and other metal carbonyls. J. Am. Chem. Soc. 1976, 98, 5728-5729.

(10) Jang, J. H.; Lee, J. G.; Lee, H.; Xie, Y.; Schaefer, H. F., III. Molecular Structures and Vibrational Frequencies of Iron Carbonyls: $\mathrm{Fe}(\mathrm{CO})_{5}, \mathrm{Fe}_{2}(\mathrm{CO})_{9}$, and $\mathrm{Fe}_{3}(\mathrm{CO})_{12}$. J. Phys. Chem. A 1998, 102, 5298-5304.

(11) Cahoon, J. F.; Sawyer, K. R.; Schlegel, J. P.; Harris, C. B. Determining Transition-State Geometries in Liquids Using 2D-IR. Science 2008, 319, 1820-1823.

(12) Couzijn, E. P. A.; Slootweg, J. C.; Ehlers, A. W.; Lammertsma, K. J. Stereomutation of Pentavalent Compounds: Validating the Berry Pseudorotation, Redressing Ugi's Turnstile Rotation, and Revealing the Two- and Three-Arm Turnstiles. J. Am. Chem. Soc. 2010, 132, 18127-18140.

(13) Jiang, Y.; Lee, T.; Rose-Petruck, G. Structure of Solvated $\mathrm{Fe}(\mathrm{CO})_{5}$ : FTIR Measurements and Density Functional Theory Calculations. J. Phys. Chem. A 2003, 107, 7524-7538.

(14) Rose-Petruck (ref 13) assigned the higher-frequency bands to overtones, but we prefer the assignment to isotope bands, particularly because of the excellent force field analysis.

(15) Bor, G. Infrared Spectroscopy Studies on Metal Carbonyl Compounds, XII. ${ }^{13} \mathrm{CO}$ Isotopic Studies with Iron Pentacarbonyl. Inorg. Chim. Acta 1969, 3, 191-195.

(16) The DFT-computed energy difference between the $D_{3 h}$ and $C_{4 v}$ structures compares very well to benchmark calculations at the $\operatorname{CCSD}(\mathrm{T})$ level; see the Supporting Information for details and data.

(17) Hamm, P.; Zanni, M. Concepts and Methods of 2D Infrared Spectroscopy; Cambridge University Press: Cambridge, U.K., 2011.

(18) Le Sueur, A. L.; Horness, R. E.; Thielges, M. C. Applications of Two-Dimensional Infrared Spectroscopy. Analyst 2015, 140, 43364349.

(19) Baiz, C. R.; McRobbie, P. L.; Anna, J. M.; Geva, E.; Kubarych, K. J. Two-Dimensional Infrared Spectroscopy of Metal Carbonyls. Acc. Chem. Res. 2009, 42, 1395-1404.

(20) Turner, J. J.; Bühl, M. The Infrared Dynamics of Iron Diene Complexes. J. Phys. Chem. A 2018, 122, 3497-3505.

(21) Rogers, M. T.; Woodbrey, J. C. A Proton Magnetic Resonance Study of Hindered Internal Rotation in Some N,N-Dimethylamides. J. Phys. Chem. 1962, 66, 540-546.

(22) Kim, Y. S.; Hochstrasser, R. M. Comparison of Linear and 2D IR Spectra in the Presence of Fast Exchange. J. Phys. Chem. B 2006, 110, 8531-8534.

(23) Grevels, F.-W.; Jacke, J.; Klotzbücher, W. E.; Krüger, C.; Seevogel, K.; Tsay, Y. H. Dynamic Processes on the IR Time Scale:
Coalescence of CO Stretching Vibrational Bands in $\left[\left(\eta^{4}\right.\right.$-Diene $) \mathrm{Fe}$ $\left.(\mathrm{CO})_{3}\right]$ Complexes. Angew. Chem., Int. Ed. Engl. 1987, 26, 885-887.

(24) Grevels, F.-W.; Jacke, J.; Seevogel, K. Dynamics of Metal Carbonyls on the Infrared Timescale: Coalescence of CO stretching Vibrational Bands. J. Mol. Struct. 1988, 174, 107-112.

(25) Kruczynski, L.; Takats, J. Intramolecular Rearrangement in $(\eta$ Diene)tricarbonyliron and -Ruthenium compounds: A Carbon-13 Nuclear Magnetic Resonance Study. Inorg. Chem. 1976, 15, 31403147.

(26) Grevels, F.-W.; Kerpen, K.; Klotzbücher, W. E.; McClung, R. E.; Russell, G.; Viotte, M.; Schaffner, K. The Very Low Barrier of CO Site Exchange in Tricarbonyl $\left(\eta^{4}-1,4\right.$-cylclooctadiene $)$ iron: Picosecond Kinetics in Solution Investigated by Line Shape Simulation of the (CO) IR Bands and Complementary Evidence from the Course of ${ }^{13} \mathrm{CO}$ Incorporation in a Low-Temperature Matrix. J. Am. Chem. Soc. 1998, 120, 10423-10433.

(27) Wood, K. A.; Strauss, H. L. Broadening and Shifts of Vibrational Bands Due to the Effect of Thermal Chemical Reactions. J. Phys. Chem. 1990, 94, 5677-5684.

(28) MacPhail, R. A.; Strauss, H. L. Can the Bloch equations describe the vibrational spectra of a reacting molecule? J. Chem. Phys. $1985,82,1156-1166$.

(29) Strauss, H. L. Changes of the Carbonyl Stretching Spectra with Temperature. J. Am. Chem. Soc. 1992, 114, 905-907.

(30) Zoerb, M. C.; Harris, C. B. A Simulation Program for Dynamic Infrared (IR) Spectra. J. Chem. Educ. 2013, 90, 506-507.

(31) Fröbel, S.; Appel, S.; Ganter, C.; Gilch, P. Extracting Picosecond Time Constants from Steady-State Spectroscopy: A Physical Chemistry Experiment. J. Chem. Educ. 2013, 90, 1082-1086.

(32) Giordano, A. N.; Morton, S. M.; Jensen, L.; Lear, B. J. Direct Test of the Equivalency of Dynamic IR and Dynamic Raman Spectroscopies as Techniques for Observing Ultrafast Molecular Dynamics. J. Phys. Chem. A 2013, 117, 2067-2074.

(33) Giordano, A. N.; Lear, B. J. Solvent versus Temperature Control over the Infrared Band Shape and Position in $\mathrm{Fe}(\mathrm{CO})_{3}\left(\eta^{4}\right.$ Ligand) Complexes. J. Phys. Chem. A 2013, 117, 12313-12319.

(34) Giordano, A. N.; Lear, B. J. Comparing the Energetic and Dynamic Contributions of Solvent to Very Low Barrier Isomerization Using Dynamic Steady-State Vibrational Spectroscopy. J. Phys. Chem. A 2015, 119, 3545-3555.

(35) The formula to estimate the Voigt width was taken from: Olivero, J. J.; Longbothum, R. L. Empirical fits to the Voigt line width: A brief review. J. Quant. Spectrosc. Radiat. Transfer 1977, 17, 233-236.

(36) Rose-Petruck and colleagues (ref 13) also performed similar DFT calculations, but we have now traced the evolution of the CO stretching vibrations along the reaction pathway to show the smooth shift of the bands. It should be noted that the harmonic vibrational frequencies are not strictly defined for the intermediate structures, as they are not stationary. However, the gradients building up from this shift torsional motion are small, and the $\mathrm{CO}$ stretching vibrations are well-decoupled from such torsional twists.

(37) (a) Poliakoff, M.; Howdle, S. M.; Healy, M. A.; Whalley, J. M. Photochemistry and Spectroscopy in Supercritical Fluids near Room Temperature. In Proceedings of the International Symposium on Supercritical Fluids; Perrut, M., Ed.; Institut National Polytechnique de Lorraine, 1988; p. 967. (b) Howdle, S. M.; Poliakoff, M. Organometallic photochemistry in supercritical fluids: the reaction of $\mathrm{H}_{2}$ with $\left[\left(\eta^{5}-\mathrm{C}_{5} \mathrm{H}_{5}\right) \mathrm{M}(\mathrm{CO})_{3}\right](\mathrm{M}=\mathrm{Re}$ and $\mathrm{Mn})$ and the formation of a non-classical dihydrogen complex of manganese(I). J. Chem. Soc., Chem. Commun. 1989, 1099-1101. (c) Howdle, S. M.; Healy, M. A.; Poliakoff, M. Organometallic Chemistry in Supercritical Fluids: The Generation and Detection of Dinitrogen and Nonclassical Dihydrogen Complexes of Group 6, 7, and 8 Transition Metals at Room Temperature. J. Am. Chem. Soc. 1990, 112, 4804-4813. (d) Poliakoff, M.; Howdle, S. M.; Kazarian, S. G. Vibrational Spectroscopy in Supercritical Fluids: From Analysis and Hydrogen Bonding to Polymers and Synthesis. Angew. Chem., Int. Ed. Engl. 1995, 34, 1275-1295. (e) Cooper, A. I.; Poliakoff, M. High-Pressure Reactions in Polyethylene Films, A New Development in Matrix Isolation. The 
Photochemical Reaction of $\mathrm{Fe}(\mathrm{CO})_{5}$ with $\mathrm{N}_{2}$ and the Thermal Reaction of $\mathrm{Fe}(\mathrm{CO})_{4}\left(\mathrm{~N}_{2}\right)$ with $\mathrm{H}_{2}$. Chem. Phys. Lett. 1993, 212, 611616. (f) Banister, J. A.; Cooper, A. I.; Howdle, S. M.; Jobling, M.; Poliakoff, M. Solvent-Free Photochemical Activation of $\mathrm{CH}_{4}, \mathrm{C}_{2} \mathrm{H}_{4}$, and $\mathrm{C}_{2} \mathrm{H}_{6}$ by $\left(\mathrm{C}_{5} \mathrm{Me}_{5}\right) \operatorname{Ir}(\mathrm{CO})_{2}$ in Supercritical Fluid Solution. Organometallics 1996, 15, 1804-1812. (g) Portius, P.; George, M. W. Studying Highly Reactive Organometallic Complexes with Infrared Spectroscopy: Matrix Isolation, Liquefied Noble Gases, Supercritical Fluids and Time-resolved IR Spectroscopy. In Comprehensive Organometallic Chemistry III; Crabtree, R. H., Mingos, D. M. P., Eds.; Elsevier: Oxford, U.K., 2007; pp 263-278. 